Postprint of Plant Physiology and Biochemistry Volume 102, May 2016, Pages 141-150

DOI: https://doi.org/10.1016/j.plaphy.2016.02.025

\title{
Characterization of a small acyl-CoA-binding protein (ACBP) from Helianthus annuus $L$. and its binding affinities
}

Jose A. Aznar-Moreno ${ }^{a}$, Mónica Venegas-Calerón ${ }^{b}$, Zhi-Yan Du ${ }^{c}$, Rafael Garcés ${ }^{b}$, Julian A. Tanner $^{d}$, Mee-Len Chye ${ }^{c}$, Enrique Martínez-Force ${ }^{b}$ and Joaquín J. Salas ${ }^{b}$.

*to whom correspondence should be addressed

${ }^{a}$ Department of Biochemistry \& Molecular Biophysics, Kansas State University, 141 Chalmers Hall, Manhattan, KS 66506.

${ }^{\mathrm{b}}$ Instituto de la Grasa (CSIC), Campus Universitario Pablo de Olavide, Ctra. de Utrera Km 1, 41013 Sevilla, Spain.

'School of Biological Sciences, The University of Hong Kong, Pokfulam, Hong Kong.

${ }^{d}$ Department of Biochemistry, The University of Hong Kong, Pokfulam, Hong Kong.

Running title: Helianthus annuus small acyl-CoA-binding protein

Keywords: Acyl-CoA, acyl-CoA binding protein, phosphatidic acid, phosphatidylcholine, phospholipids, sunflower.

Email: jjsalas@ig.csic.es

Tlf: +34954611550 


\begin{abstract}
Acyl-CoA-binding proteins (ACBPs) bind to acyl-CoA esters and promote their interaction with other proteins, lipids and cell structures. Small class I ACBPs have been identified in different plants, such as Arabidopsis thaliana (AtACBP6), Brassica napus (BnACBP) and Oryza sativa (OsACBP1, OsACBP2, OsACBP3), and they are capable of binding to different acyl-CoA esters and phospholipids. Here we characterize HaACBP6, a class I ACBP expressed in sunflower (Helianthus annuus) tissues, studying the specificity of its corresponding recombinant HaACBP6 protein towards various acyl-CoA esters and phospholipids in vitro, particularly using isothermal titration calorimetry and protein phospholipid binding assays. This protein binds with high affinity to de novo synthetized derivatives palmitoly-CoA, stearoyl-CoA and oleoyl-CoA $\left(\mathrm{K}_{d} 0.29\right.$, 0.14 and $0.15 \mu \mathrm{M}$ respectively). On the contrary, it showed lower affinity towards linoleoyl-CoA (Kd $5.6 \mu \mathrm{M})$. Moreover, rHaACBP6 binds to different phosphatidylcholine species (dipalmitoyl-PC, dioleoyl-PC and dilinoleoyl-PC), yet it displays no affinity towards other phospholipids like lyso-PC, phosphatidic acid and lysophosphatidic acid derivatives. In the light of these results, the possible involvement of this protein in sunflower oil synthesis is considered.
\end{abstract}

Key words: Acyl-CoA, acyl-CoA binding protein, phosphatidic acid, phosphatidylcholine, phospholipids, sunflower. 


\section{Introduction}

In higher plants, most de novo fatty acid (FA) biosynthesis takes place in plastids due to the action of the fatty acid synthase complex (Harwood, 2005). The FAs synthesized are subsequently exported to the cytosol and activated to their acyl-CoA esters by acyl-CoA synthetases (Schnurr et al., 2002; Zhao et al., 2010). In developing oil seeds, the main products of plastidial FA biosynthesis are oleoyl-CoA (18:1-CoA), palmitoyl-CoA (16:0-CoA) and stearoylCoA (18:0-CoA: Bates et al., 2009), intermediates that can be used to synthesise glycerolipids in the endoplasmic reticulum (ER): (i) via acyl editing through the action of reticular lysophosphatidylcholine acyltransferases (LPCAT); or (ii), via the Kennedy pathway, where different acyltransferases use them to acylate glycerol-3-phosphate, generating triacylglycerols (TAG) and other glycerolipids (Bates et al., 2009). All these processes involve the transfer of acyl-CoA esters between organelles, and their subsequent interaction with different enzymes and substrates (Moreau et al., 1998; Li-Beisson et al., 2010).

The transfer of lipids across the cytosol is thought to be mediated by two groups of proteins: lipid-transfer proteins (Kader, 1996) and acyl-CoA binding proteins (ACBPs: Xiao and Chye, 2009). The latter group of proteins are present in plants and animals, and they are believed to protect the acyl-CoA pool from enzymes such as hydrolases or acyl-CoA carboxylases (Knudsen et al., 2000; Faergeman and Knudsen, 2002; Xiao et al., 2009). The mammalian ACBPs were those first characterized (Guidotti et al., 1983), prior to those from yeast and plants (Rose et al., 1992; Hills et al., 1994), proteins with a highly conserved acyl-CoA binding ( $A C B$ ) domain formed by four helical folds (Teilum et al., 2005; Taskinen et al., 2007; Raboanatahiry et al., 2015). Studies of ACBP activity showed that overexpression of a recombinant bovine ACBP increased the acyl-CoA pool size and phospholipid content in yeast (Mandrup et al., 1993), which suggests that ACBPs are necessary to maintain the cellular acylCoA pool and for glycerolipid biosynthesis in vivo. Conversely, the composition and quantity of very long-chain fatty acids is modified when ACBP is depleted in yeast. Likewise, sphingolipid synthesis was dampened in these conditions, which affected vesicular trafficking and membrane assembly, and resulted in growth retardation (Gaigg et al., 2001; Faergeman et al., 2004). These observations indicate that ACBPs are involved in the metabolism of acyl-CoA esters and their lipid derivatives. 
The first plant ACBPs were characterized in Brassica napus (BnACBP: Hills et al., 1994) and Arabidopsis (AtACBP: Engeseth et al., 1996; Pacovsky, 1996; Leung et al., 2004), and ACBP genes from Oryza sativa have also since been described (OsACBP; Meng et al., 2011). The plant ACBP family is divided into three groups that contain four distinct classes of proteins, each with different structural domains (Meng et al., 2011). Group I embraces class I ACBPs, small soluble $10 \mathrm{kDa}$ proteins located in the cytosol and that only contain the ACB domain common to all ACBPs. The second group are the class IV ACBPs, which contain Kelch motifs that potentially facilitate protein-protein interactions (Leung et al., 2004; Li et al., 2008). Class II and class III ACBPs are included in the third group, proteins with $\mathrm{N}$-terminal membrane association domains. In addition, class II proteins possess a domain of C-terminal Ankyrin repeats that drive interactions with other proteins (Li and Chye, 2004; Xiao et al., 2009; Gao et al., 2009; Gao et al., 2010). While class III ACBPs contain only the ACB domain, members of this class are larger than those from class I and they also have a distinct subcellular localization (Leung et al., 2004; Leung et al., 2006). In Arabidopsis, there are six members of the ACBP family (AtACBP1 to AtACBP6), of which only one is a 10 kDa class I protein (tACBP6: Xiao and Chye, 2011), whereas three analogous proteins were identified in O. sativa (OsACBP1 to OsACBP3: Meng et al., 2014). Recombinant AtACBP6, as well as its OsACBP homologues, bind to acyl-CoA esters, as well as to saturated and unsaturated phosphatidylcholine (PC: Chen et al., 2008; Xiao et al., 2008; Meng et al., 2014). Another class I ACBP is the BnACBP, which increases glycerol-3-phosphate acyltransferase activity in vitro (Brown et al., 1998), as well as showing affinity for different acyl-CoAs and stimulating the synthesis of PC by LPCAT (Yurchenko et al., 2009). These studies show that these small proteins play a role in plant lipid biosynthesis and that they may influence the final composition of seed oils.

Here, we report the isolation and characterization of HaACBP6, a small (10 kDa) sunflower homologue of AtACBP6 and BnACBP. The aim of this study was to gain insight into the interactions of HaACBP6 with saturated, unsaturated and polyunsaturated acyl-CoAs, using isothermal titration calorimetry (ITC) and different phospholipid species. In addition, studies on the subcellular localization of HaACBP6 confirmed it to be a cytosolic protein. We discuss the possible functions of this protein in seed oil biosynthesis in the light of these results.

\section{Materials and methods}




\subsection{Plant material}

Sunflower (Helianthus annuus L.) seeds from the CAS-6 wild-type sunflower line were germinated in wet perlite at $25{ }^{\circ} \mathrm{C}$ and kept in a germination chamber for 2 weeks. Subsequently, the seedlings were moved to growth chambers equipped with fertirrigation, and they were maintained at $25 / 15{ }^{\circ} \mathrm{C}$ (day/night) on $16 \mathrm{~h}$ photoperiod cycles with a photon flux density of $300 \mu \mathrm{mol} \cdot \mathrm{m}^{-2} \cdot \mathrm{s}^{-1}$ until the vegetative tissues or developing seeds were harvested.

Tobacco (Nicotiana benthamiana) seeds were germinated and grown in similar chambers equipped with fertirrigation units under the same conditions until harvest of vegetative tissues for agroinfiltration.

\subsection{Cloning the $C D N A$ encoding sunflower ACBP6}

Developing sunflower seeds (approximately $0.4 \mathrm{~g}$ ) were harvested at $15 \mathrm{DAF}$ and ground in a precooled sterile mortar and pestle in liquid $N_{2}$. The seed mRNA was isolated in $33 \mu \mathrm{LTE}$ buffer (10 mM Tris-HCl [pH 8.0], 1 mM EDTA) using the Spectrum Plant Total RNA kit and the GenElute mRNA Miniprep Kit (Sigma, St. Louis, MO), and cDNAs were then obtained using a Ready-To-Go TPrimed First Strand Kit (Amersham Bioscience, Roosendaal, The Netherlands).

Using the TBLASTN algorithm (Altschul et al., 1997), the cDNA encoding Arabidopsis thaliana ACBP6 was used to search sunflower expressed sequence tags (ESTs) available in public databases in order to identify putative mRNAs that might encode sunflower ACBP6 homologues. As such, ESTs corresponding to the 5'- and $3^{\prime}$ - fragments of this cDNA were identified. To match the end-fragments corresponding to the same mRNA by PCR, primers with internal Sacl and Xmal restriction sites were designed, SaclACBP6-F and XmalACBP6-R, respectively (Table 1; all the primers were synthesized by Eurofins MWG Operon, Germany). Accordingly, a fragment encoding the entire HaACBP6 was amplified by PCR and cloned into the pMBL-T Easy vector (Molecular Bio Laboratory, Córdoba, España), sequencing several clones on both strands (SECUGEN, Madrid, Spain). The identity of the clone was confirmed using the BLAST software (Altschul et al., 1997) and the full-length cDNA encoding HaACBP6 was obtained, including the ATG and STOP codons, and deposited in GENBANK under accession number KJ826407. The plasmid bearing HaACBP6 was then digested with Sacl-Xmal and the DNA fragment was ligated into the Sacl-Xmal sites of pQE-80L (Qiagen, Hilden, Germany) to produce a fusion protein with a (His) $)_{6}$-tag at its $\mathrm{N}$-terminus. DNA sequence analysis confirmed 
the correct reading frame of the sequence and the resulting construct was designated as pQE80-HaACBP6. The recombinant plasmid was expressed in the Escherichia coli strain BL21(DE3)Star pLysS.

\subsection{Protein sequence analyses}

Homologous protein sequences of HaACBP6 were retrieved using the BLASTP program (www.ncbi.nlm.nih.gov) and they were aligned with other amino acid sequences encoding ACBPs deposited at GENBANK using the ClustalX v.2.0.10 program under default settings (Larkin et al., 2007). These alignments were used to generate a phylogenetic tree based on the neighbour-joining algorithm (Saitou and Nei, 1987), and the resulting 'phenogram' was extracted using the MEGA 5.0 program (Tamura et al., 2011).

\subsection{Modelling the three-dimensional structure of sunflower ACBP6}

Homology modelling studies were performed using the Swiss Model server (Schwede et al., 2003; http://swissmodel.expasy.org/) and JPred prediction server (Cuff and Barton, 2000). The sequence used as a template was a human ACBP (Accession number P07108, gi118276), and the template chosen was that most homologous to ACBP6 for which an X-ray structure was available (PDB Entry 2fj9: Taskinen et al., 2007), showing $45.35 \%$ sequence identity with HaACBP6. SWISS-MODEL was used as a first approximation, employing the project (optimise) mode's default parameters and the structures were visualized using Swiss-PDB Viewer (Guex and Peitsch, 1997).

\subsection{Quantitative real-time $P C R$}

The cDNAs from developing sunflower seeds $(16,20,25$ and 30 DAF), roots, stems, green cotyledons (2, 4 and 7 days after imbibition - DAI) and leaves were obtained from $5 \mu \mathrm{g}$ of total RNA isolated from the different tissues as described above. The cDNAs were analysed by real-time quantitative PCR (RT-QPCR) using specific primer pairs (QHaACBP6-F and QHaACBP6-R: Table 1) and SYBR Green I (QuantiTect SYBR Green PCR Kit, Qiagen, Crawley, UK) in a MiniOpticon system to monitor the resulting fluorescence (Bio-Rad, Hercules, CA). The reaction mixture was heated to $50{ }^{\circ} \mathrm{C}$ for $2 \mathrm{~min}$ and then to $95{ }^{\circ} \mathrm{C}$ for $15 \mathrm{~min}$ before subjecting it to 40 PCR cycles of: $94{ }^{\circ} \mathrm{C}$ for $15 \mathrm{~s} ; 61^{\circ} \mathrm{C}$ for $30 \mathrm{~s}$; and $72{ }^{\circ} \mathrm{C}$ for $30 \mathrm{~s}$. Calibration curves were drawn up using serial dilutions of the cDNAs and the Livak method was applied to calculate the relative 
expression of the samples (Livak and Schmittgen, 2001). The sunflower actin gene HaACT1 (GenBank Accession number FJ487620) was amplified with the specific QHaActin-F4 and QHaActin-R4 primer as an internal reference to normalize the relative amount of cDNA in each sample (Table 1).

\subsection{Expression and purification of rHaACBPs in E. coli}

Cultures of E. coli BL21(DE3)Star pLysS cells harbouring pQE80-HaACBP6 were grown in LB media (1\% Bacto Tryptone, $0.5 \%$ yeast extract, $1 \% \mathrm{NaCl}[\mathrm{pH}$ 7]) supplemented with 100 $\mu \mathrm{g} / \mathrm{mL}$ ampicillin and $34 \mu \mathrm{g} / \mathrm{mL}$ chloramphenicol, and the liquid cultures (300ml) were shaken vigorously at $37{ }^{\circ} \mathrm{C}$. The expression of the recombinant gene was induced by adding $0.4 \mathrm{mM}$ isopropylthio-6-D-galactoside (IPTG) when the culture $\mathrm{OD}_{600}$ reached a value of 0.4 . The cells were then harvested by centrifugation after a $5 \mathrm{~h}$ incubation and resuspended in $8 \mathrm{~mL}$ native lysis buffer (50 mM NaH${ }_{2} \mathrm{PO}_{4}$ [pH 8.0], $300 \mathrm{mM} \mathrm{NaCl}, 10 \mathrm{mM}$ imidazole). The cells were sonicated on ice (ten $10 \mathrm{~s}$ bursts at 200-300 W with a $10 \mathrm{~s}$ cooling period between each one) and the recombinant protein purified from the cleared lysate $\left(10,000 \times g\right.$ for $1 \mathrm{~h}$ at $\left.4{ }^{\circ} \mathrm{C}\right)$ on a 1 $\mathrm{mL}$ Ni-NTA agarose column (QIAGEN). The protein extract was loaded onto a previously equilibrated column and the column was then washed with 5 volumes of wash buffer $(50 \mathrm{mM}$ $\mathrm{NaH}_{2} \mathrm{PO}_{4}$ [pH 8.0], $300 \mathrm{mM} \mathrm{NaCl}, 20 \mathrm{mM}$ imidazole). The bound proteins were eluted with $2 \mathrm{~mL}$ of native elution buffer (50 mM NaH $\mathrm{PO}_{4}$ [pH 8.0], $300 \mathrm{mM} \mathrm{NaCl}, 250 \mathrm{mM}$ imidazole) and the eluted sample was dialyzed against the ITC binding buffer $\left(50 \mathrm{mM} \mathrm{K}{ }_{2} \mathrm{HPO}_{4}\right.$ [pH 7.6], $0.3 \mathrm{mM}$ EDTA and $175 \mathrm{mM} \mathrm{KCl}$ : Srivastava et al., 1997). The purified proteins were concentrated using Amicon Ultra-15 Centrifugal Filters of (molecular weight cut of 3KDa, Millipore) and the protein concentration was finally determined by the Bradford method (1976).

\subsection{Analysis of E. coli expressed His-tagged recombinant proteins in Western blots}

Proteins were electrophoretically transferred to Hybond Enhanced Chemiluminescence membranes (Amersham Bioscience) from SDS-PAGE gels in a Trans-Blot $^{\circledR}$ cell (Bio-Rad) following the manufacturer's instructions. Western blots was performed as described by Sambrook et al. (1989) and probed with anti-(His) 6 antibodies (Amersham, GE) for $1 \mathrm{~h}$ at room temperature. The antibody binding was then detected using the ECL Western-Blotting Detection Kit (Amersham Bioscience) to visualize the (His) ${ }_{6}$-tagged recombinant proteins. 


\subsection{Isothermal titration calorimetry (ITC) to investigate binding to acyl-CoA esters}

ITC experiments were performed in a MicroCal iTC $_{200}$ system (MicroCal). The acyl-CoA esters (Avanti Polar Lipids) and recombinant HaACBP6 protein used in this study were prepared in ITC binding buffer and degassed under vacuum (with stirring) to avoid bubble formation, according to the manufacturer's instructions (GE Healthcare). Volumes of $1.5 \mu \mathrm{L}$ of the acyl-CoA ester solution $(250 \mu \mathrm{M})$ were injected at $150 \mathrm{~s}$ intervals into the cell containing $500 \mu \mathrm{L}$ of the protein solution $(12.5 \mu \mathrm{M})$ at $30^{\circ} \mathrm{C}$. All the experimental data were analyzed using Microcal ORIGIN7 software (OriginLab Corporation, Northampton, USA) and the dissociation constants $\left(K_{d}\right)$ were obtained by non-linear regression fitting of the isotherm data based on a one-set of sites model.

\subsection{Protein-lipid binding assays}

The binding between rHaACBPs and lipids was examined as described previously (Du et al., 2010). In these assays, various phospholipids and lysophospholipids were spotted onto a nitrocellulose filter (Amersham Bioscience) and incubated for $1 \mathrm{~h}$ at room temperature in the dark. The filters were then blocked for $1 \mathrm{~h}$ in Tris-Buffered saline buffer (TBS: $140 \mathrm{mM} \mathrm{NaCl}, 2.7$ $\mathrm{mM} \mathrm{KCl}, 10 \mathrm{mM} \mathrm{Na}_{2} \mathrm{HPO}_{4}, 1.8 \mathrm{mM} \mathrm{KH}_{2} \mathrm{PO}_{4}$ [pH 7.4]) supplemented with 1\% non-fat milk (BioRad) and incubated for $2 \mathrm{~h}$ with rHaACBP6 $(1 \mu \mathrm{g} / \mathrm{mL}$ final concentration) in the blocking buffer. Subsequently, the filters were washed twice with TTBS (TBS buffer supplemented with $0.1 \%$ Tween 20), $10 \mathrm{~min}$ each wash, and they were then incubated with anti-(His) 6 antibodies (Amersham Bioscience) for $1 \mathrm{~h}$ at room temperature. After three washes with TTBS, the antibody was detected using the ECL Western-Blotting Detection Kit (Amersham Bioscience) to determine protein-lipid binding.

2.10. Construction of plasmids encoding green fluorescent protein-tagged HaACBP6 and agroinfiltration into tobacco leaf epidermal cells

Bioinformatics programs were used to predict the subcellular localization of HaACBP6, to identify target regions that could potentially be disrupted by translational fusion to the green fluorescent protein (GFP) and to identify putative transmembrane regions: PSORT (http://psort.hgc.jp/form.html) and TMHMM (http://www.cbs.dtu.dk/services/TMHMM-2.0/). The full-length open reading frames of GFP and HaACBP6 were amplified using specific primer pairs (XmalGFP-F/SalIGFP-R and XmalACBP6-F/ACBP6-GFP-R, respectively: Table 1), and 
HaACBP6-GFP was generated by PCR splicing using the amplified sequences as templates. First, HaACBP6 was generated using the XmalACBP6-F and ACBP6-GFP-R primers (with the stop codon removed) and then, GFP was generated using the GFP-ACBP6-F and SallGFP-R primers. Finally, both PCR products were mixed and used as a template to generate HaACBP6-GFP using the XmalACBP6-F and SallGFP-R primers (Table 1). The resulting PCR product was cloned into PMBL-T and its sequence confirmed. The fusion gene was subcloned into an Agrobacterium expression vector, pSa13 (Gao et al., 2010), which was then used to transform Agrobacterium tumefaciens strain GV 3101. This plant transformation vector harbours kanamycin and streptomycin resistant selectable markers. The fidelity of the construct was again confirmed by DNA sequence analysis before further use. The verified Agrobacterium transformants were then used to agroinfiltrate leaves of 6 -week-old tobacco ( $N$. benthamiana) plants as described elsewhere (Kapila et al., 1997). Leaf epidermal cells were then examined under a confocal laserscanning microscope equipped with helium/neon lasers.

\subsection{Confocal laser scanning microscopy}

Confocal laser scanning microscopy (CLSM) images of tobacco leaf cells were obtained on a Leica DM RBE microscope using a 63x Plan Apochromat oil-immersion objective and a TCS SP2 scanning head (Leica, Wetzlar, Germany). Confocal images were acquired as a z-series of representative cells, and single optical sections that were saved as $512 \times 512$-pixel digital images and analysed with the LEICA TCN NT software package (Version 2.61). All fluorescence images shown in this work are representative of $>20$ cells from at least three independent transformations.

\section{Results and Discussion}

\subsection{Sequence analysis of ACBP6 from sunflower}

A $0.27 \mathrm{~kb}$ cDNA encoding an ACBP was amplified from developing sunflower kernels and it was named HaACBP6 based on its strong similarity to the Arabidopsis homologue, AtACBP6. This gene encoded a protein of 90 amino acids with a predicted molecular weight of $10.86 \mathrm{kDa}$, a PI value of 5.40 and $72 \%$ predicted solubility (Seqtools 8.4, Rasmussen). When the amino acid sequence of HaACBP6 was aligned with its homologues from other plants (Fig. 1). The key 
residues involved in the interaction with the acyl-CoA are well defined (Neess et al., 2015). So $40 \%$ of the energy of this interaction came from the electrostatic attraction between some lysine and tyrosine groups of the ACBP and the phosphate group of the acyl-CoA molecule (Kragelund et al., 1999). In sunflower these corresponded to highly conserved K15, Y30, K34 and $\mathrm{K} 56$. Furthermore, there was also interaction between the protein and the adenine group of acyl-CoA due to phenylalanine and tyrosin residues that matched the F33 and Y75 from sunflower. All these residues in the acyl-CoA binding pocket were highly conserved across species (Figure 1). The amino acid sequence for HaACBP6 showed closest homology to Brassica napus $(78 \%)$ and $A$. thaliana (75\%) proteins, whereas the identity to the other protein sequences analysed remained below $70 \%$. On the basis of our data and that for ACBP sequences from other species, a phylogenetic tree was generated using the MEGA 5.0 program (Fig. 2). Unsurprisingly, the protein encoded by HaACBP6 was found very close to the AtACBP6 and BnACBP class I ACBPs. Moreover, when small ACBP isoforms from microalgae were also included in the tree, two families of proteins were evident corresponding to the Chlorophyta and Bryophyta, clearly differentiated from the higher plant species.

\subsection{Homology modelling for HaACBP6}

To investigate the secondary structure of $\mathrm{HaACBP6}$, we used the methods available on the JPred prediction servers (Cuff and Barton, 2000). The predicted structure obtained for this protein corresponded to the typical four-helix secondary structure reported for other ACBPS (Fig. 3A), as confirmed by crystallography studies on the class I ACBPs from Plasmodium falciparum (Van Aalten et al., 2001), yeast (Teilum et al., 2005) and human (Taskinen et al., 2007). In plants, this structure was also predicted by computational studies in four ACBP homologues found in Brassica napus (Raboanatahiry et al., 2015).

The secondary structure of HaACBP6 was used to search for homologous structures represented in the 3D database and all the proposed structural homologues found were members of the ACBP superfamily. A representation of the 3D structure displaying the fourhelix pattern (Fig. 3Ba and b) was obtained with the online Swiss Model program (Schwede et al., 2003; http://swissmodel.expasy.org/). The model shows two regions with the conserved amino acids mentioned in section 3.1 at the surface of the protein that promote proteinsubstrate interactions, corresponding to the acyl-CoA pocket (blue Fig. $3 \mathrm{Bc}$ ) and the region involved in the lipid interaction, in which residues of methionine, leucine and alanine 
(Kragelund et al., 1999) interact with the acyl chains of lipids stabilizing them (orange: Fig. 3Bc). This model showed that the HaACP6 protein displayed a structure analogous to other functional forms previously described and so, supported that fact that it was a functional ACBP that probably plays a role in the lipid metabolism of sunflower.

\subsection{Studies on the expression of sunflower ACBP6}

The HaACBP6 mRNA was expressed ubiquitously in sunflower, being detected in vegetative tissues, germinating cotyledons and developing seeds (Fig. 4). This profile fits well with its housekeeping activity to maintain the acyl-CoA pool, and the protection it provides during seed development, seedling establishment and vegetative growth. Moreover, there was a correlation between the expression of HaACBP6 and the size of the acyl-CoA pool, whereby HaACBP6 was expressed most strongly in developing seeds at 30 days after flowering (DAF) when the acyl-CoA concentration and rate of oil synthesis in seed tissue were maximal (Aznar-Moreno et al., 2013). Similarly, HaACBP6 expression was strongest in germinating cotyledons at 4 DAl, matching the maximum acyl-CoA accumulation in this organ (Aznar-Moreno et al., 2013). These results agreed well with those obtained in other species: AtACBP6 is expressed in the seedling, leaves, roots and siliques (Chen et al., 2008; Xiao et al., 2009); and $B n A C B P$ displays a similar profile of expression in developing embryos, with maximal expression coinciding with the peak of TAG accumulation (Engeseth et al., 1996). These data support the hypothesis that HaACBP6 is involved in acyl-CoA transport during the process of oil synthesis and degradation.

\subsection{Expression of sunflower rHaACBP6 in Escherichia coli}

Soluble rHaACBP6 protein was expressed strongly in E. coli and the protein was purified from the soluble bacterial fraction as a (His) ${ }_{6}$-tagged protein on a Ni-NTA affinity column. SDSPAGE of the different fractions showed the purified rHaACBP6 matched the predicted molecular weight of $10.86 \mathrm{KDa}$ (Fig. 5A) and it was recognised in western blots by polyclonal antibodies raised against the (His) 6 tag (Fig. 5B). The purified recombinant protein was used in ITC and filter-binding assays to study its affinity towards different acyl-CoA esters and phospholipids, respectively.

\subsection{Studies of the interaction of HaACBP6 with different acyl-CoA esters}


The primary function proposed for ACBPs is to bind to different acyl-CoA esters and regulate their metabolism. Since these proteins are expressed strongly in developing sunflower embryos, we investigated the affinity of rHaACBP6 for different acyl-CoA esters important in TAG synthesis in order to define its possible involvement in the accumulation of sunflower oil. ITC assays in vitro (Supplementary material) were used to examine the interaction between acyl-CoA esters and rHaACBP6 (Table 2). This technique has been used previously to determine the thermodynamic parameters of the interactions between different molecules in solution and to check the affinity of AtACBPs and OsACBPs towards different acyl-CoA esters (Meng et al., 2014; Hsiao et al., 2014). First, we tested the ability of rHaACBP6 to bind to 16:0-CoA, 18:0-CoA and 18:1-CoA esters as in sunflower seeds, these FAs represent the main de novo FAs synthesized in the plastid and exported to the cytosol as acyl-CoA esters. Moreover, we studied rHaACBP6 binding to 18:2-CoA, 18:3-CoA and arachidoyl-CoA (20:0-CoA), important acyl-CoAs in plant lipid metabolism that are also found in the leaves and developing seeds from sunflower (Aznar-Moreno et al., 2013). Affinity can be measured by the dissociation constant $\left(K_{d}\right)$, which is related to the Gibbs energy released in the interaction. Results in table 2 were similar to those obtained for AtACBP6 (Hsiao et al., 2014), with $\triangle \mathrm{G}$ around $-10 \mathrm{Kcal} / \mathrm{mol}$ and most $\mathrm{K}_{\mathrm{d}}$ values under the $\mu \mathrm{M}$ range. Moreover, $\mathrm{n}$ values of 1 and lower indicates that one molecule of protein interacts with a single molecule of acyl-CoA. In these studies, rHaACBP6 was seen to bind strongly to acyl-CoAs derived from plastidial synthesis which displayed low $K_{d}$ values (16:0-CoA; 0.29, 18:0-CoA; 0.14 and 18:1-CoA; 0.15, all in $\mu \mathrm{M})$, whereas with 20:0-CoA displayed lower affinity $\left(K_{d} 1.4 \mu M\right)$. Interestingly, $r$ HaACBP6 had the lowest affinity towards 18:2-CoA ( $K_{d} 5.6$ $\mu \mathrm{M})$, the most abundant fatty acid in sunflower oil. In the case of 18:3-CoA the $K_{d}$ value was $0.75 \mu \mathrm{M}$, and so the protein bound to it weaker than de novo synthetized acyl-CoAs but stronger than to $18: 2-\operatorname{CoA}$. These experiments were run in duplicate and produced similar results.

Sunflower oil synthesis requires largescale incorporation of 18:1 and 18:2 acyl-CoA derivatives into the TAG fraction. The $18: 1$ fatty acid is mainly incorporated into PC in the ER (Bates and Browse, 2012), whereas 18:2 is synthesized in the $s n-2$ position of PC by oleate desaturase (FAD2: Li-Beisson et al., 2010). These fatty acids can be released from PC into an acyl-CoA pool by the acyl editing pathway, which increases the rate of polyunsaturated acylCoA that can be incorporated into other glycerolipids by acyltransferases. In this regard, the most abundant acyl-CoA found in the pool of acyl-CoA in sunflower was reported to be 
18:1-CoA not 18:2-CoA (Aznar-Moreno et al., 2013). Since rHaACBP6 has a weaker affinity for 18:2-COA, it would appear that there is a correlation between the specificity of HaACBP6 and the concentration of this metabolite in the acyl-CoA pool. Moreover, this data also supports the hypothesis that the exchange of this acyl-CoA ester between PC and the acyl-CoA pool may be limited in sunflower, and that this fatty acid is directly incorporated into TAG or diacylglycerols by the action of phospholipid:diacylglycerol acyltransferase (PDAT) or phosphatidylcholine:diacylglycerol cholinephosphotransferase (PDCT), respectively, rather than being released from PC, which would reduce its concentration in the acyl-CoA pool. In this regard, the existence of other forms of ACBP6 with higher specificity towards 18:2-CoA in sunflower was investigated. Southern blots seemed to indicate that this gene has a single copy in this specie, similarly to Arabidopsis (supplementary data), although an active role of other types of ACBP in the transport of 18:2-CoA cannot be discarded. The affinity of rHaACBP6 towards the other acyl-CoAs fits well with their presence in the acyl-CoA seed pool, so 16:0-CoA, 18:0-COA and 18:1-CoA are the products of the de novo fatty acid synthesis in seeds. They are largely produced by plastids and they have to be metabolized quickly into glycerolipids. The high level of affinity towards these substrates fits well with their high metabolic flow through the lipid synthesis pathway in developing seeds and it is in agreement with previous results found in other species (Hsiao et al., 2014). HaACBP6 protein was also present in vegetative tissues, where 16:0-CoA and 18:3-CoA were the most abundant acyl-CoA intermediates. Accordingly, the high affinity of rHaACBP6 towards those metabolites fits well with its role in their protection and transport associated with glycerolipid synthesis in leaf tissue and green germinating cotyledons (Aznar-Moreno et al., 2013).

In Arabidopsis, AtACBP6 preferentially binds 16:0-CoA and 18:2-CoA rather than 18:1CoA, and 18:3-CoA (Xiao and Chye, 2011; Hsiao et al., 2014). As AtACBP4 and AtACBP5 can also bind these acyl-CoA esters and both have been localized in the cytosol, these proteins could also participate in the cytosolic trafficking of acyl-CoAs (Xiao and Chye, 2009). Indeed, recent studies showed that AtACBP6 binds to acyl-CoA esters with stronger affinity than AtACBP4 and AtACBP5 (Hsiao et al., 2014). Furthermore, double and triple mutants of acbp4/acbp5/acbp6 showed that mutations in Atacbp6 caused major seed weight loss with a strong accumulation of 18:1-CoA in the embryos (Hsiao et al., 2014), indicative of a principal role of small class I ACBPs in the process of oil accumulation. In rice, the cytosolic OsACBP1 binds 18:1-CoA rather than 
18:2-CoA and 18:3-CoA, while OsACBP2 and OsACBP3 bind to 18:3-CoA and have not yet been tested for their affinity for 18:1-CoA or 18:2-CoA (Meng et al., 2011).

\subsection{Studies of the affinity of HaACBP6 towards different phospholipid species}

As indicated above, ACBPs contains a lipid-binding domain that promotes their interaction with acyl-CoAs. The interaction between rHaACBP6 and different phospholipids was studied in vitro in filter binding assays. In these experiments we found that rHaACBP6 binds to PC but it did not display any affinity towards PA or lysophospholipids like lyso-PC (LPC) or lysoPA (LPA: Fig. 6A). Furthermore, when serial dilutions of PC were analyzed the magnitude of the interaction of rHaACBP6 with the different phospholipid species could be seen. Accordingly, rHaACBP6 showed stronger affinity to unsaturated PC species (dioleoyl-CoA and dilinoleoyl-PC) and weaker interactions with dipalmitoyl-PC (Fig. 6C). Moreover, the affinity to dimyristoyl-PC and distearoyl-PC was much weaker than that for the aforementioned substrates (Fig. 6). The main difference between $\mathrm{HaACBP6}$ and the Arabidopsis isoform was in their affinity towards dipalmitoyl-PC, which was higher in the former. As reported for AtACBP6, rHaACBP6 did not bind PA, LPA acid and LPC (Fig. 6A: Chen et al., 2008). By contrast, OsACBP1 and OsACBP2 do bind to saturated and unsaturated species of PC and PA (Meng et al., 2014).

The most abundant phospholipid in developing seeds is PC, which fulfils important structural and metabolic roles in plant physiology (Wallis and Browse, 2002; Li-Beisson et al., 2010). This glycerolipid is the substrate of different enzymes located in the ER that strongly influence the final FA composition of oilseeds, such as FAD2 or PDCT (Lu et al., 2009; Li-Beisson et al., 2010). The PC species found in the first stages of sunflower seed development are mainly palmitoyl-linoleoyl-PC and palmitoyl-oleoyl-PC. However, once oil deposition commences the expression of HaACBP6 augments, and oleate and linoleate become more abundant, increasing the accumulation of dilinoleoyl-PC, oleoyl-linoleoyl-PC and dioleoyl-PC species (Salas et al., 2006 a,b). The affinity of rHaACBP6 for different PC species indicates that it could participate in the binding of acyl-CoA and PC, which are very important in FA desaturation and oil synthesis. Indeed, there is an increase in PA at the expense of PC in transgenic $A$. thaliana overexpressing AtACBP6 under freezing stress in leaves (Chen et al., 2008), whilst the opposite effect was observed in flowers (Liao et al., 2014). Furthermore, the up-regulation of LPCAT when AtACBP6 is overexpressed in flowers again points to a role for this ACBP in the LPCAT mediated maintenance of the intracellular pools of acyl-CoA and PC (Liao et al., 2014). These observations 
indicate the relationship between this small protein and PC. Moreover, the small BnACBP can also bind to acyl-CoA esters in vitro, promoting the incorporation of 18:1-CoA into PC through the action of LPCAT (Yurchenko et al., 2009). In mammals, the small ACBP increased GPAT activity, as well as the accumulation of phospholipids and TAGs, suggesting that this protein enhances the transfer of acyl-CoA esters for TAG synthesis (Huang et al., 2005; Yang et al., 2001). Together, these results suggest a key role for HaACBP6 in the cytosolic transport of PC, in maintaining the exchange between acyl-CoA esters and PC, and in transferring acyl-CoA during TAG synthesis.

\subsection{Localization of HaACBP6}

The cytosolic localization of AtACBP6 was confirmed with an autofluorescence-tag and in western blots of subcellular fractions probed with ACBP6-specific antibodies (Chen et al., 2008). More recently, their OsACBP1 and OsACBP2 homologues were also localized to the cytosol while OsACBP3 displayed multiple subcellular localizations (Meng et al., 2014). In this study, we prepared a construct encoding the full-length HaACBP6 protein fused to the green fluorescent protein (GFP) at its $C$-terminus and it was transiently expressed in tobacco leaves (a construct designated as HaACBP6-GFP). HaACBP6 was predicted to be a cytosolic protein by PSORT (http://psort.hgc.jp/form.html) with a confidence level score of 0.65 (reflecting a reliable prediction) and indeed, HaACBP6-GFP was seen to localize to the cytosol and nucleus (Fig. 7). The size exclusion of nuclear pores (Görlich and Mattaj, 1996) would allow this protein HaACBP6-GFP ( 38 kDa) to cross to the nucleus by passive diffusion, and these results are similar to those reported for fusion proteins of the $10 \mathrm{kDa}$ Arabidopsis and rice ACBP (Chen et al., 2008; Meng et al., 2014). This localization of HaACBP6 fits well with its interaction between the cytosolic acyl-CoA pool and phospholipids from different organelles, especially the ER, the site of glycerolipid synthesis in developing seeds.

\section{Conclusions}

The gene corresponding to a class I ACBP from sunflower was cloned and it was shown to be phylogenetically close to the class I ACBP's from Arabidopsis and Brassica. The protein encoded by this gene was located in the cytosol and nucleus, and it was readily overexpressed in the soluble fraction of $\mathrm{E}$. coli, facilitating its production and purification. HaACBP6 was expressed in all the tissues analysed with levels of expression particularly high in the cotyledons 
and developing seeds, tissues in which lipid synthesis or degradation is very active. The size and composition of the acyl-CoA pools of these tissues has been determined previously (AznarMoreno et al., 2013), and the levels of HaACBP6 expression correlated with the pool size of these metabolites. Moreover, rHaACBP6 binds with high affinity to 16:0-CoA, 18:1-CoA and 18:0-CoA, which pointed to a role in the metabolization of the de novo synthesized fatty acids. It displayed lower affinities towards 18:2-CoA and 20:0-CoA. The low affinity of HaACBP6 towards $18: 2-$ CoA was particularly unexpected given that $18: 2$ is the most abundant fatty acid in sunflower oil. This deficiency of affinity could be balanced by the presence of other ACBP forms in sunflower cytosol showing lower $K_{d}$ values for this intermediate, although southern blot studies pointed that there was a single copy of ACBP6 gene in sunflower genome. This result could also point to a weaker contribution of direct acylation of the glycerol backbone to the synthesis of TAGs in sunflower. Moreover, studies of its capacity to bind to different phospholipids showed that the affinity of HaACBP6 was strongest towards the unsaturated PC species typically present in developing sunflower seeds, confirming the role of this protein in the interaction between this phospholipid and the acyl-CoA pool.

\section{Acknowledgements}

This work was supported by the MINECO and FEDER (Project AGL2011-23187), a joint Consejo Superior de Investigaciones Cientificas/Research Grant Council of Hong Kong (CSIC/RGC) research award (Project 2011HK0008; S-HK006/12), and the Wilson and Amelia Wong Endowment Fund.

\section{References}

Altschul, S.F., Madden, T.L., Schaffer, A.A., Zhang, J., Zhang, Z., Miller, W., Lipman, D.J., 1997. Gapped BLAST and PSI-BLAST: a new generation of protein database search programs. Nucleic Acids Res. 25, 3389-3402.

Aznar-Moreno, J.A., Martinez-Force, E., Venegas-Calerón, M., Garcés, R., Salas, J.J., 2013. Changes in acyl-coenzyme A pools in sunflower seeds with modified fatty acid composition. Phytochem. 87, 39-50. 
Aznar-Moreno, J.A., Venegas-Calerón, M., Martinez-Force, E., Garcés, R., Robert, M., Satinder, K.D., Salas, J.J., 2014. Sunflower (Helianthus annuus) long-chain acyl-coenzyme A synthetases expressed at high levels in developing seeds. Physiologia Plantarum 150: 363-373.

Bates, P.D., Browse, J., 2012. The significance of different diacylglycerol synthesis pathway on plant oil composition and bioengineering. Front. Plant Sci. 147: 1-11.

Bates, P.D., Durret, T.P., Ohlrogge, J.B., Pollard, M., 2009. Analysis of acyl fluxes through multiple pathways of triacylglycerol synthesis in developing soybean embryos. Plant Physiol. 150, 55-72.

Bradford, M.M., 1976. A rapid and sensitive method for the quantitation of microgram quantities of protein utilizing the principle of protein-dye binding. Anal. Biochem. 72, 248-254.

Brown, A.P., Johnson, P., Rawsthorne, S., Hills, M.J., 1998. Expression and properties of acylCoA binding protein from Brassica napus. Plant Physiol. Biochem. 36: 629-635.

Chen, Q.F., Xiao, S., Chye, M.L., 2008. Overexpression of the Arabidopsis 10-Kilodalton acylcoenzyme A-binding protein ACBP6 enhances freezing tolerance. Plant Physiol. 148, 304315.

Cuff, J.A., Barton, G.J., 2000. Application of enhanced multiple sequence alignment profiles to improve protein secondary structure prediction. Proteins: Struct. Funct. Genet. 40, 502511.

Du, Z.Y., Xiao, S., Chen, Q.F., Chye, M.L., 2010. Depletion of the membrane-associated AcylCoenzyme A-Binding Protein ACBP1 enhances the ability of cold acclimation in Arabidopsis. Plant Physiol. 152, 1585-1597.

Engeseth, N.J., Pacovsky, R.S., Newman, T., Ohlrogge, J.B., 1996. Characterization of an acylCoA binding protein from Arabidopsis thaliana. Arch. Biochem. Biophys. 331, 55-62.

Faergeman, N. J., Feddersen, S., Christiansen, J. K., Larsen, M. K., Schneiter, R., Ungermann, C., Mutenda, K., Roepstorff, P. and Knudsen, J., 2004. Acyl-CoA-binding protein, Acb1p, is required for normal vacuole function and ceramide synthesis in Saccharomyces cerevisiae. Biochem. J. 380, 907-918

Faergeman, N.J., Knudsen, J., 2002. Acyl-CoA binding protein is an essential protein in mammalian cell lines. Biochem. J. 368, 679-82. 
Gaigg, B., Neergaard, T.B.F., Schneiter, R., Hansen, J.K., Faergeman, N.J., Jensen, N.A., Andersen, J.R., Friis, J., Sandhoff, R., Schroder, H.D., Knudsen, J., 2001. Depletion of acyl coenzyme A-binding protein affects sphingolipid synthesis and causes vesicle accumulation and membrane defects in Saccharomyces cerevisiae, Mol. Biol. Cell. 12, 1147-1160.

Gao, W., Li, H.Y., Xiao, S., Chye, M.L., 2010. Acyl-CoA-binding protein 2 binds lysophospholipase 2 and lysoPC to promote tolerance to cadmium-induced oxidative stress in transgenic Arabidopsis. Plant J. 62, 989-1003.

Gao W., Xiao S., Li H.Y., Tsao S.W., Chye M.L., 2009. Arabidopsis thaliana acyl-CoA-binding protein ACBP2 interacts with a heavy-metal-binding farnesylated protein AtFP6. New Phytol. 181: 89-102.

Görlich, D., Mattaj, I.W., 1996. Nucleocytoplasmic transport. Science 271, 1513-1518.

Guex, R.E.F., Peitsch, M.C., 1997. Swiss Model and Swiss Pdb Viewer: an environment for comparative protein modelling. Electrophoresis 18, 2714-2723.

Guidotti, A., Forchetti, C.M., Corda, M.G., Konkel, D., Bennett, C.D., Costa, E., 1983. Isolation, characterization, and purification to homogeneity of an endogenous polypeptide with agonistic action on benzodiazepine receptors. Proc. Natl. Acad. Sci. USA 80, 3531-3535.

Harwood, J.L., 2005. Fatty acid biosynthesis, in: Murphy, D.J. (Ed.), Plant Lipids: Biology, Utilisation and Manipulation. Blackwell Publishing, Oxford. pp 27-66.

Hills, M.J., Dann, R., Lydiate, D., Sharpe, A., 1994. Molecular cloning of a cDNA from Brassica napus L. For a homologue of acyl-CoA binding protein. Plant Mol. Biol. 25, 917-920.

Hsiao, A.S., Haslam, R.P., Michaelson, L.V., Liao, P., Chen, Q.F., Sooriyaarachchi, S., Mowbray, S.,L., Napier, J.A., Tanner, J.A., Chye, M.L., 2014. Arabidopsis cytosolic acyl-CoA-binding proteins ACBP4, ACBP5 and ACBP6 have overlapping but distinct roles in seed development. Biosci. Rep. 34, 865-877.

Huang, H., Atshaves, B.P., Frolov, A., Kier, A.B., Schroeder, F., 2005. Acyl-coenzyme A binding protein expression alters liver fatty acyl-coenzyme A metabolism. Biochem. 44, 1028210297.

Kader, J.C., 1996. Lipid-transfer proteins in plants. Ann. Rev. of Plant Physiol. and Plant Mol. Biol. $47,627-654$.

Kapila, J., De Rycke, R., Van Montagu, M., Angenon, G., 1997. An Agrobacterium-mediated transient gene expression system for intact leaves. Plant Sci. 122, 101-108. 
Knudsen, J., Neergaard, T.B., Gaigg, B., Jensen, M.V., Hansen, J.K., 2000. Role of acyl-CoA binding protein in acyl-CoA metabolism and acyl-CoA-mediated cell signaling. J. Nutr. 130, 294S-298S.

Kragelund, B.B., Poulsen, F.M., Andersen, K.V., Baldursson, T., Krøll , $\perp$ J.B., Neergård, T.B., Jepsen, J., Roepstorff, P., Kristiansen, K., Poulsen, F.M., Knudsen, J., 1999. Conserved residues and their role in the structure, function, and stability of acyl-coenzyme $A$ binding protein. Biochem. 38, 2386-2394.

Larkin, M.A., Blackshields, G., Brown, N.P., Chenna, R., McGettigan, P.A., McWilliam, H., Valentin, F., Wallace, I.M., Wilm, A., Lopez, R., Thompson, J.D., Gibson, T.J., Higgins, D.G., 2007. Clustal W. Clustal X version 2.0. Bioinformatics 23, 2947-2948.

Leung, K.C., Li, H.Y., Mishra, G., Chye, M.L., 2004. ACBP4 and ACBP5, novel Arabidopsis acylCoA-binding proteins with kelch motifs that bind oleoyl-CoA. Plant Mol. Biol. 55, 297309.

Leung, K.C., Li, H.Y., Xiao, S., Tse, M.H., Chye, M.L., 2006. Arabidopsis ACBP3 is an extracellularly targeted acyl-CoA-binding protein. Planta 223, 871-881.

Li, H.Y., Chye, M.L., 2004. Arabidopsis acyl-CoA-binding protein ACBP2 interacts with an ethylene-responsive element-binding protein, AtEBP, via its ankyrin repeats. Plant Mol. Biol. 54, 233-243.

Li, H.Y., Xiao, S., Chye, M.L., 2008. Ethylene- and pathogen- inducible Arabidopsis acyl-CoAbinding protein 4 interacts with an ethylene-responsive element binding protein. J. Exp. Bot. 59, 3997-4006.

Liao, P., Chen, Q.F., Chye, M.L., 2014. Transgenic Arabidopsis flowers overexpressing acyl-CoAbinding protein ACBP6 are freezing tolerance. Plant Cell Physiol. 55, 1055-1071.

Li-Beisson, Y., Shorrosh, B., Beisson, F., Andersson, M.X., Arondel, V., D. Bates, P.D., Baud, S., Bird, D., DeBono, A., Durrett, T.P., Franke, R.B., Graham, I.A., Katayama, K., Kelly, A.A., Larson, T.,Markham, J.E., Miquel, M., Molina, I., Nishida, I., Rowland, O., Samuels, L., Schmid, K.M., Wada, H., Welti, R., Xu, C., Zallot, R., Ohlrogge, J., 2010. Acyl-Lipid Metabolism. The Arabidopsis Book / American Society of Plant Biologists, 8, e0133. doi:10.1199/tab.0133.

Livak, K.J., Schmittgen, T.D., 2001. Analysis of relative gene expression data using real-time quantitative PCR and the $2^{-\Delta \Delta C T}$ method. Methods $25,402-408$. 
Lu, C., Xin, Z., Ren, Z., Miquel, M., and Browse, J. (2009). An enzyme regulating triacylglycerol composition is encoded by the ROD1 gene of Arabidopsis. Proc. Natl. Acad. Sci. USA 106, 18837-18842.

Mandrup, S., Jepsen, R., Skott, H., Rosendal, J., Hojrup, P., Kristiansen, K., Knudsen, J., 1993. Effect of heterologous expression of acyl-CoA-binding protein on acyl-CoA level and composition in yeast. Biochem. J. 290, 369-374.

Meng, W., Su, Y.C.F., Saunderds, R.M.K., Chye, M.L., 2011. The rice acyl-CoA-binding protein gene family: phylogeny, expression and functional analysis. New phytol. 4, 1170-1184.

Meng, W., Hsiao, A.S., Gao, C., Jiang, L., Chye, M.L., 2014. Subcellular localization of rice acylCoA-binding proteins (ACBPs) indicates that OsACBP6::GFP is targeted to the peroxisomes. New Physiol. 203, 469-482.

Moreau, P., Bessoule, J.J., Mongrand, S., Vincent, P.T., Cassagne, C., 1998. Lipid trafficking in plant cells. Prog. Lipid Res. 37, 371-391.

Neess, D., Bek, S., Engelsby, H., Gallego S.F., Færgeman, N.J., 2015. Long-chain acyl-CoA esters in metabolism and signaling: Role of acyl-CoA binding proteins. Prog. Lipid Res. 59, 1-25.

Pacovsky, R.S., 1996. Arabidopsis thaliana acyl-CoA binding protein: structure, functions, genetics. PhD Thesis, Michigan State University.

Raboanatahity, N. H., Lu, G., Li, M., 2015. Computational Prediction of acyl-CoA Binding Proteins Structure in Brassica napus. PLOSone 10, 1-21.

Rose, T. M., Schultz, E. R., Todaro, G. J., 1992. Molecular cloning of the gene for the yeast homolog $(\mathrm{ACB})$ of diazepam binding inhibitor/endozepine/acyl-CoA-binding protein. Proc. Natl. Acad. Sci. USA 89: 11287-11291.

Saitou, N., Nei, M., 1987. The neighbour-joining method - a new method for reconstructing phylogenetic trees. Mol. Biol. Evol. 4, 406-425.

Salas, J.J., Martinez-Force, E., Garces, R., 2006a. Accumulation of phospholipids and glycolipids in seed kernels of different sunflower mutants (Helianthus annuus). J. American Oil Chem. Soc. 83, 539-545.

Salas, J.J., Martinez-Force, E., Garces, R., 2006b. Phospholipids molecular profiles in the seed kernels from different sunflower (Helianthus annuus) mutants. Lipids 48, 805-811.

Sambrook, J., Fristsh, E.F., Maniatis, T., 1989. Molecular cloning. A laboratory Manual, $2^{\text {nd }}$ ed. Cold Spring Harbor Laboratory Press. Cold Spring Harbor. New York. 
Schnurr, J.A., Shockey, J.M., de Boer, G-J., Browse, J.A., 2002. Fatty acid export from chloroplast. Molecular characterization of a major plastidial acyl-coenzyme A synthetase from Arabidopsis. Plant Physiol. 129, 1700-1709.

Schwede, T., Kopp, J., Guex, N., Peitsch, M.C., 2003. SWISS-MODEL: an automated protein homology-modeling server. Nucleic Acids Res. 31, 3381-3385.

Srivastava, D.K., Wang, S., Peterson, K.L., 1997. Isothermal titration microcalorimetric studies for the binding of octenoyl-CoA to medium chain acyl-CoA dehydrogenase. Biochem. 36, 6359-6366.

Tamura, K., Peterson, D., Peterson, N., Stecher, G., Nei, M., Kumar, S., 2011. MEGA5: Molecular evolutionary genetics analysis using maximum likelihood, evolutionary distance, and maximum parsimony methods. Mol. Biol. Evol. 28, 2731-2739.

Taskinen, J.P., Van Aalten, D.M., Knudsen, J., Wierenga, R.K., 2007. High resolution crystal structures of unliganded and liganded human liver ACBP reveal a new mode of binding for the acyl-CoA ligand. Proteins 66, 229-238.

Teilum, K., Thormann, T., Caterer, N.R., Poulsen, H.I., Jensen, P.H., Knudsen, J., Kragelund, B.B., Poulsen, F.M., 2005. Different secondary structure elements as scaffold for protein folding transition states of two homologous four-helix bundles. Proteins 59, 80-90.

Van Aalten, D.M.F., Milne, K.G., Zou, J.Y., Kleywegt, G.J., Bergfors, T., Fergurson, M.A.J., Knudsen, J., Jonse, T.A., 2001. Binding site differences revealed by crystal structures of Plasmodium falciparum and bovine acyl-CoA binding protein, J. Mol. Biol. 309, 181-192.

Wallis, J.G., Browse, J., 2002. Mutants of Arabidopsis Reveals many Roles for Membrane Lipids. Prog. Lipid Res. 41, 254-278.

Xiao, S., Gao, W., Chen, Q.F., Ramalingam, S., Chye, M.L., 2008. Overexpression of membraneassociated acyl-CoA-binding protein ACBP1 enhances lead tolerance in Arabidopsis. Plant J. 54, 141-151.

Xiao, S., Chen, Q.F., Chye, M.L., 2009. Light-regulated Arabidopsis ACBP4 and ACBP5 encode cytosolic acyl-CoA-binding proteins that bind phosphatidylcholine and oleoyl-CoA ester. Plant Physiol. Biochem. 47, 926-933.

Xiao, S., Chye, M.L., 2009. An Arabidopsis family of six acyl-CoA-binding proteins has three cytosolic members. Plant Physiol. Biochem. 47, 479-84.

Xiao, S., Chye, M.L., 2011. New roles for acyl-CoA-binding proteins (ACBP) in plant development, stress responses and lipid metabolism. Prog. Lipid Res. 50, 141-151. 
Yang, Y., Pritchard, P.H., Bhuiyan, J., Seccombe, D.W., Moghadasian, M.H., 2001. Overexpression of acyl-CoA binding protein and its effects on the flux of free fatty acids in McA-RH 7777 cells. Lipids 36, 596-600.

Yurchenko, O.P., Nykiforuk, C.L., Moloney, M.M., Stahl, U., Banas, A., Styme, S., Weselake, R.J., 2009. A 10-kDa acyl-CoA-binding protein (ACBP) from Brassica napus enhances acyl exchange between acyl-CoA and phosphatidylcholine. Plant Biotechnol. J. 7, 602-610.

Zhao, L., Katavic, V., Li, F., Haughn, G.W., Kunst, L., 2010. Insertional mutant analysis reveals that long-chain acyl-CoA synthetase 1 (LACS1) but not LACS8, functionally overlaps with LACSp in Arabidopsis seed oil biosynthesis. Plant J. 64, 1048-1058. 
Tables

\section{Table 1}

Sequences of the PCR primers used in this work. The restriction sites are underlined and the letters " $F$ " and " $R$ " correspond to Forward and Reverse, respectively.

\begin{tabular}{|c|c|}
\hline Primer name & Sequence $^{a}$ \\
\hline SaclACBP6-F & $5^{\prime}$ - GAGCTCATGGGTTTGAAGGAGGACTTTG -3' \\
\hline XmalACBP6-R & $5^{\prime}$ - CCCGGGTCAAGCAGCGGCAG -3' \\
\hline QHaACBP6-F & 5' - CTTTCGTCACGAAATGGGTTTG -3' \\
\hline QHaACBP6-R & 5'- CGGTCGGTGTTCACCGGT- 3' \\
\hline XmalACBP6-F & 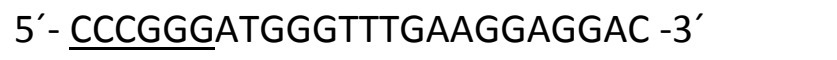 \\
\hline ACBP6-GFP-R & 5' - AGCGGCAGCGTCCATAGTATCATGGGTAGG- 3' \\
\hline GFP-ACBP6-F & 5' - CCTACCCATGATACTATGGACGCTGCCGCT- 3' \\
\hline XmaIGFP-F & $5^{\prime}$ - CCCGGGATGGTGAGCAAGGGCGAG -3' \\
\hline SalIGFP-R & 5' - GTCGACTTACTTGTACAGCTCGTC- 3' \\
\hline QHaActin-F4 & 5'- GCTAACAGGAAAAGATGACT- 3' \\
\hline QHaActin-R4 & 5' - ACTGGCATAAAGAGAAAGCACG- 3' \\
\hline
\end{tabular}




\section{Table 2}

Thermodynamic parameters resulting from studies of interaction of rHaACBP6 with different acyl-CoAs by isothermal titration calorimetry (ITC).

\begin{tabular}{lccccc}
\hline & $\mathrm{n}$ & $\begin{array}{c}\triangle \mathrm{H} \\
(\mathrm{Kcal} / \mathrm{mol})\end{array}$ & $\begin{array}{c}\triangle \mathrm{S} \\
\left(\mathrm{cal} / \mathrm{mol} \mathrm{K}^{-1}\right)\end{array}$ & $\begin{array}{c}\triangle \mathrm{G} \\
(\mathrm{Kcal} / \mathrm{mol})\end{array}$ & $\begin{array}{c}\mathrm{Kd} \\
(\mu \mathrm{M})\end{array}$ \\
\hline 16:0-CoA & 0.6 & -3.7 & 22 & -10.3 & 0.29 \\
18:0-CoA & 0.5 & -4.9 & 17 & -9.8 & 0.14 \\
18:1-CoA & 0.9 & -3.1 & 23 & -9.8 & 0.15 \\
18:2-CoA & 0.6 & -3.6 & 19 & -9.3 & 5.60 \\
18:3-CoA & 0.9 & -1.9 & 30 & -10.8 & 0.75 \\
20:0-CoA & 1.0 & -3.0 & 18 & -8.4 & 1.40 \\
\hline
\end{tabular}




\section{Figure Legends}

Fig. 1. Sequence alignment. Alignment of the HaACBP6 (Helianthus annuus L.) amino acid sequences against At, Arabidopsis thaliana (gi|15222465|); Bn, Brassica napus (gi|5902715|); Os, Oryza sativa (gi|115474931|, gi|218193194| and gi|115466024|); Ps, Picea sitchensis (gi|116778774|); Pp, Physcomitrella patents (gi|168013072|); and Cv, Chlorella variabilis (gi|552835471|). The amino acids in the acyl-CoA binding pocket (O) and those involved in CoA binding $(\boldsymbol{\nabla})$ are indicated. The aligned residues in white foreground on a dark background are $100 \%$ conserved bases. The residues in black on a grey background are more than $75 \%$ conserved.

Fig. 2. Phylogenetic tree of the ACBPs from different plant, bryophyte and chlorophyte species. Class II and III (ACBP1, ACBP2 and ACBP3), Class IV (ACBP4 and ACBP5) sequences from Arabidopsis thaliana were used as an out group to root the tree. The GenInfo identifiers (gi) follow the species name.

Fig. 3. Structural study of HaACBP6. A. Deduced amino acid sequence and predicted secondary structure for the sunflower HaACBP6 protein: $h$, $\alpha$-helix (high resolution crystal structure of ligand human L-ACBP). The JPred prediction server was used to generate the predicted secondary structure. B. 3D structure of HaACBP6. Ba., the terminal end is shown in blue and the C-terminal end in red. Bb, Molecular surface. Bc, Molecular surface in blue representing the acyl-CoA-binding pocket, the orange residues are involved in CoA-binding. The Swiss Model server was used to generate the structures and they were visualized using Swiss-PDB Viewer.

Fig. 4. Expression of HaACBP6 analyzed by RT-QPCR in various sunflower tissues. DAF (days after flowering), DAl (days after imbibition). The error bars represent the standard deviation $(n=3)$.

Fig. 5. Purification of recombinant Helianthus annus acyl-CoA-binding protein (rHaACBP6) from E. coli extract. A; Coomassie Blue gel of (His) ${ }_{6}$-tagged rHaACBP6 following $15 \%$ sodium dodecylsulphate-polyacrylamide gel electrophoresis (SDS-PAGE). B; Corresponding western blot probed for the $(\mathrm{His})_{6}$-tag: $\mathrm{M}$, protein standard markers; F, flow through sample; W, wash 
sample; S, eluate fraction containing the purified protein. The arrowhead denotes the $10 \mathrm{kDa}$ rHaACBP6 band.

Fig. 6. Interaction of rHaACBP6 with different phospholipid species. A, Binding of rHaACBP6 to phospholipids on a membrane. B, Diagram of the lipid species on the membrane shown in panel A. C, rHaACBP6 binding to a filter with serial dilutions of phospholipids $(50,25,12.5$ and 5 $\mu \mathrm{M})$. Phospholipids: PA, phosphatidic acid; PC, phosphatidylcholine; LPA, IysoPA; and LPC, IysoPC. Fatty acids: 14:0, myristic acid; 16:0, palmitic acid;18:0, stearic acid; 18:1, oleic acid; and 18:2, linoleic acid.

Fig. 7. Subcellular localization of HaACBP6. Confocal laser scanning microscopy images of tobacco leaves in which HaACBP6-green fluorescent protein is transiently expressed. Images in column A show GFP (row 1) and HaACBP6-GFP (row 2) in the cytosol and nucleus. Column B shows the transmitted light images. Corresponding merged images of all the cells are shown in column C. Bar $=35 \mu \mathrm{m}$. 
Fig.1

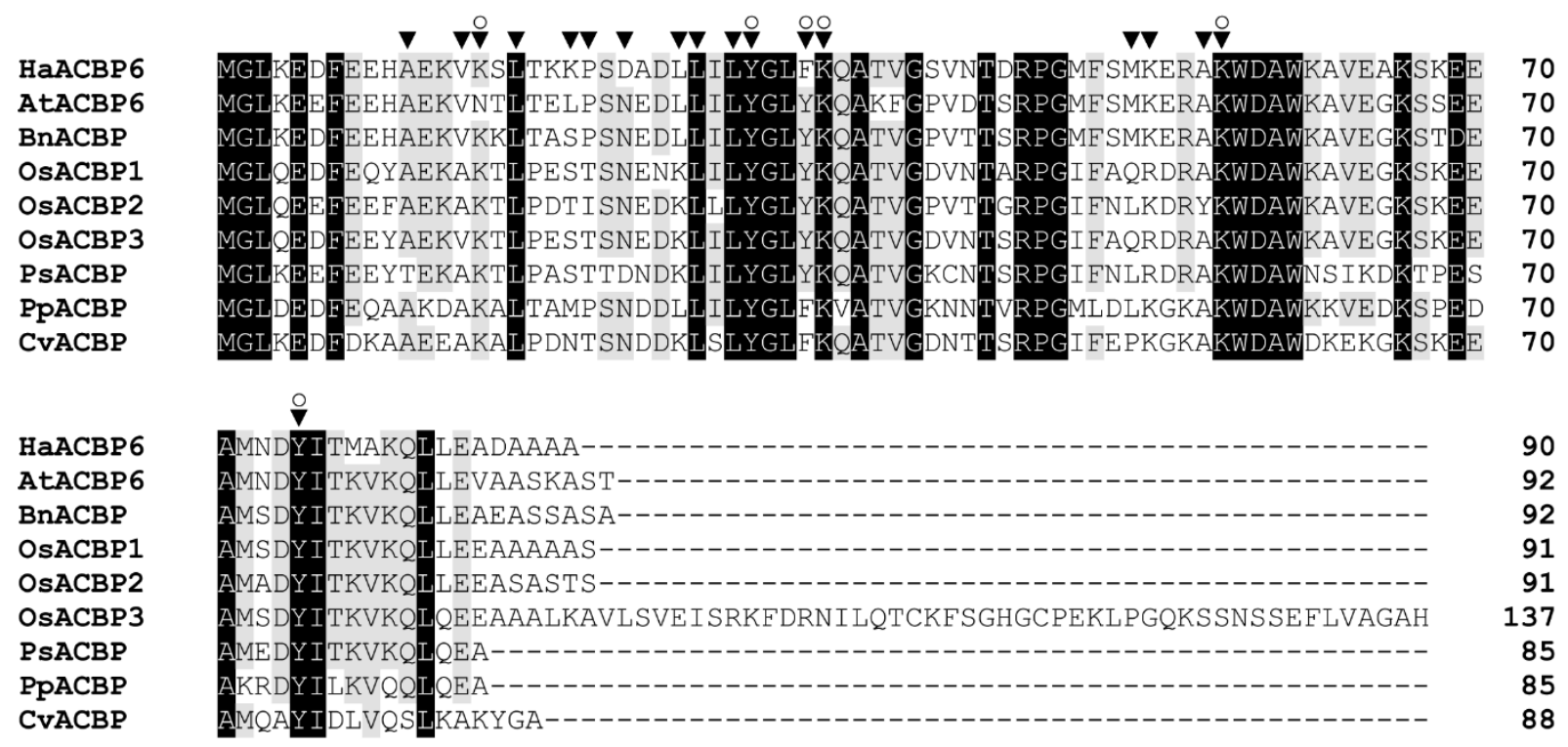


Fig 2.

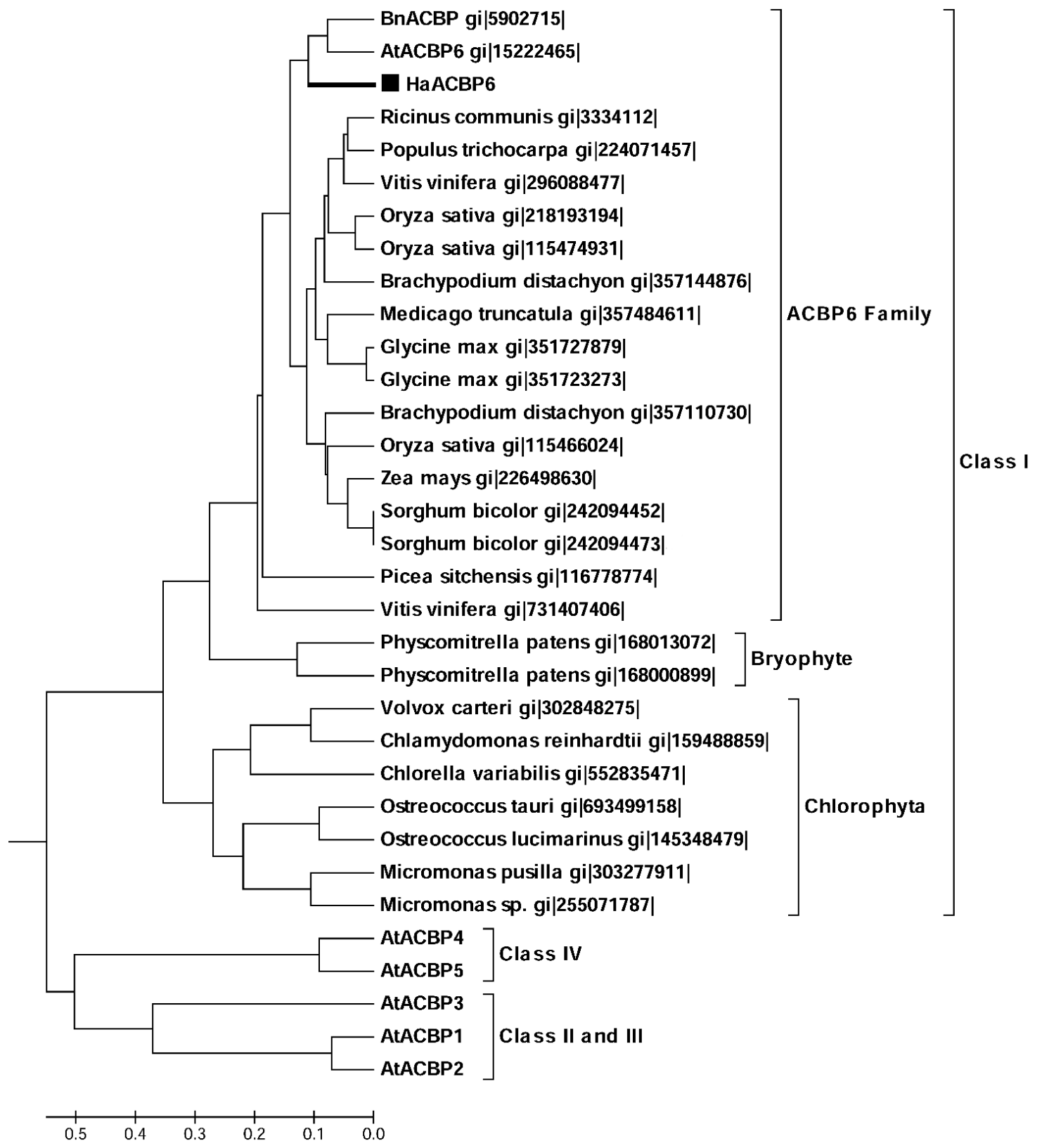


Fig.3

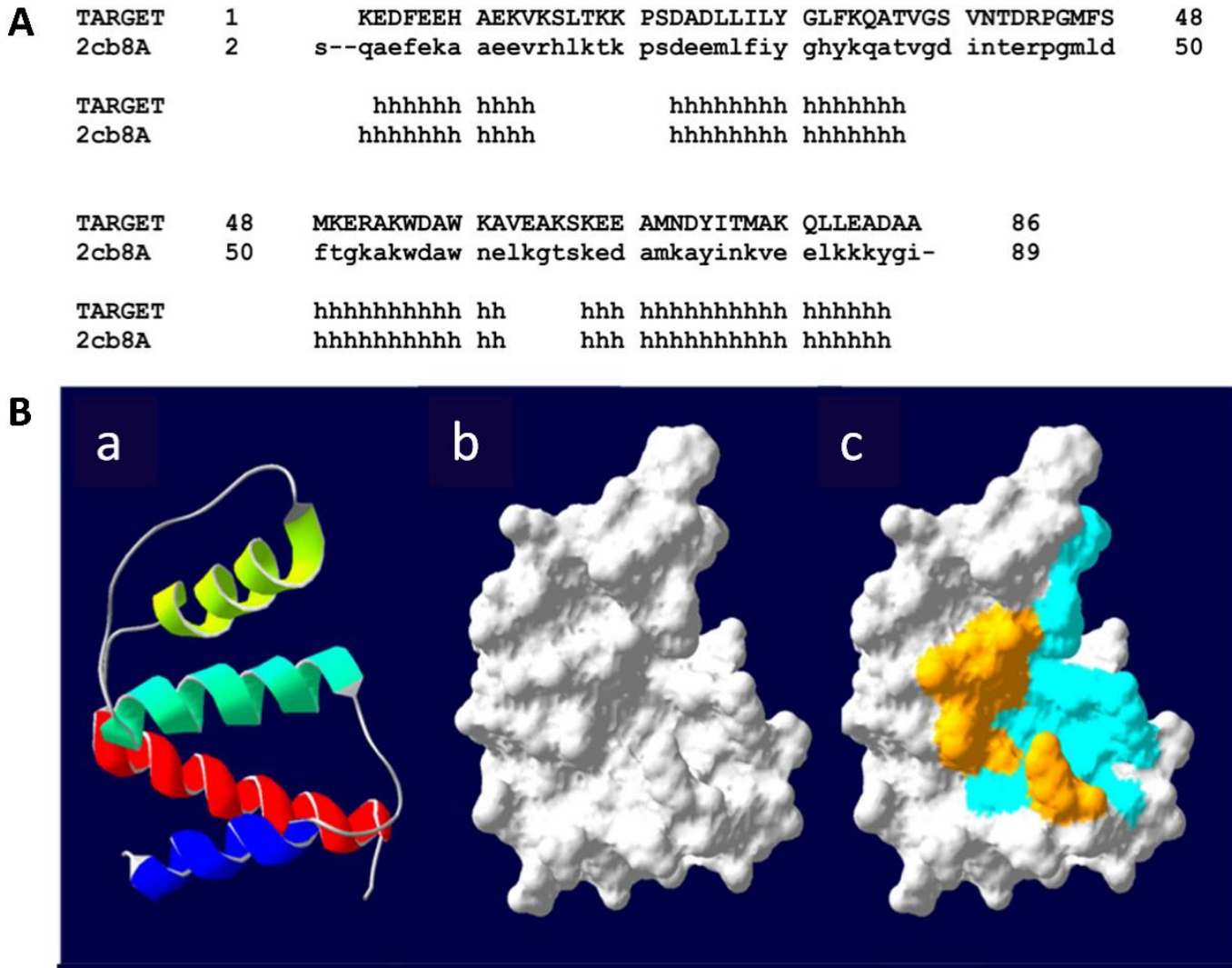


Fig. 4

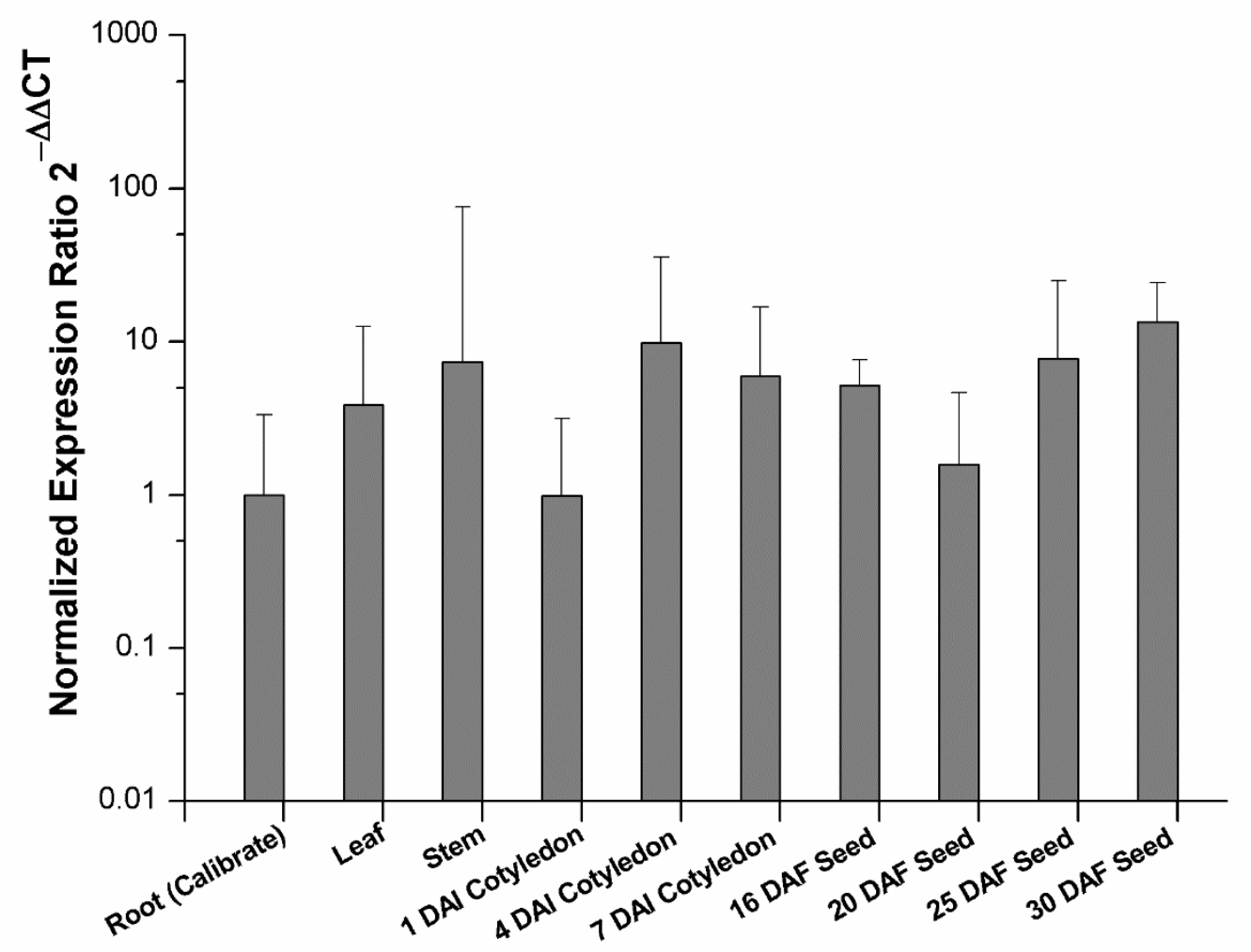


Fig. 5

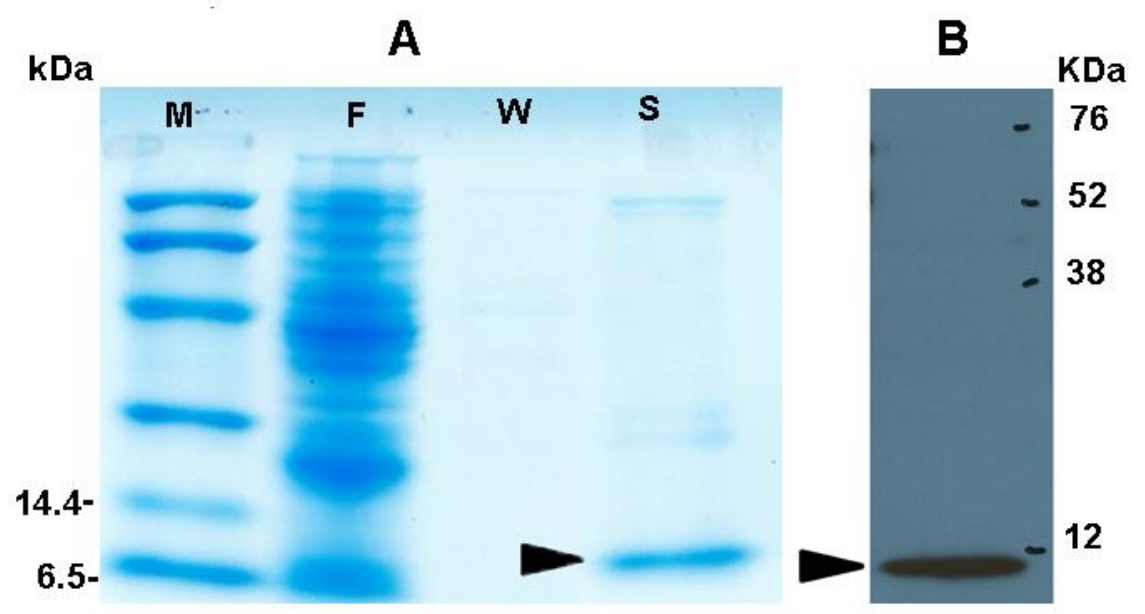


Fig. 6

A

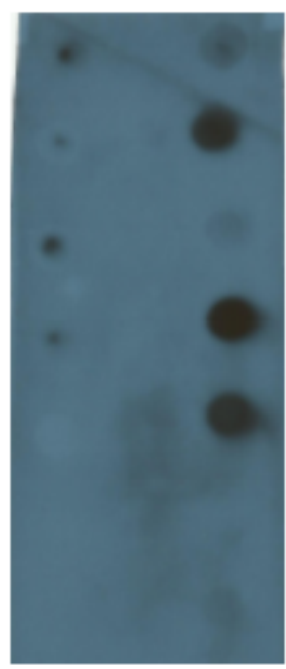

B

\begin{tabular}{c|c}
$14: 0-P A$ & $14: 0-P C$ \\
\hline $16: 0-P A$ & $16: 0-P C$ \\
\hline $18: 1-P A$ & $18: 0-P C$ \\
\hline $18: 0-$ LPA & $18: 1-P C$ \\
\hline $18: 1-$ LPA & $18: 2-P C$ \\
\hline $16: 0-$ LPC & $18: 0-$ LPC \\
\hline Control & $18: 1-$ LPC
\end{tabular}

$\begin{array}{lllll}C & 50 & 25 & 12.5 & 5[\mu \mathrm{M}]\end{array}$

16:0-PC

18:1-PC

18:2-PC 
Fig 7
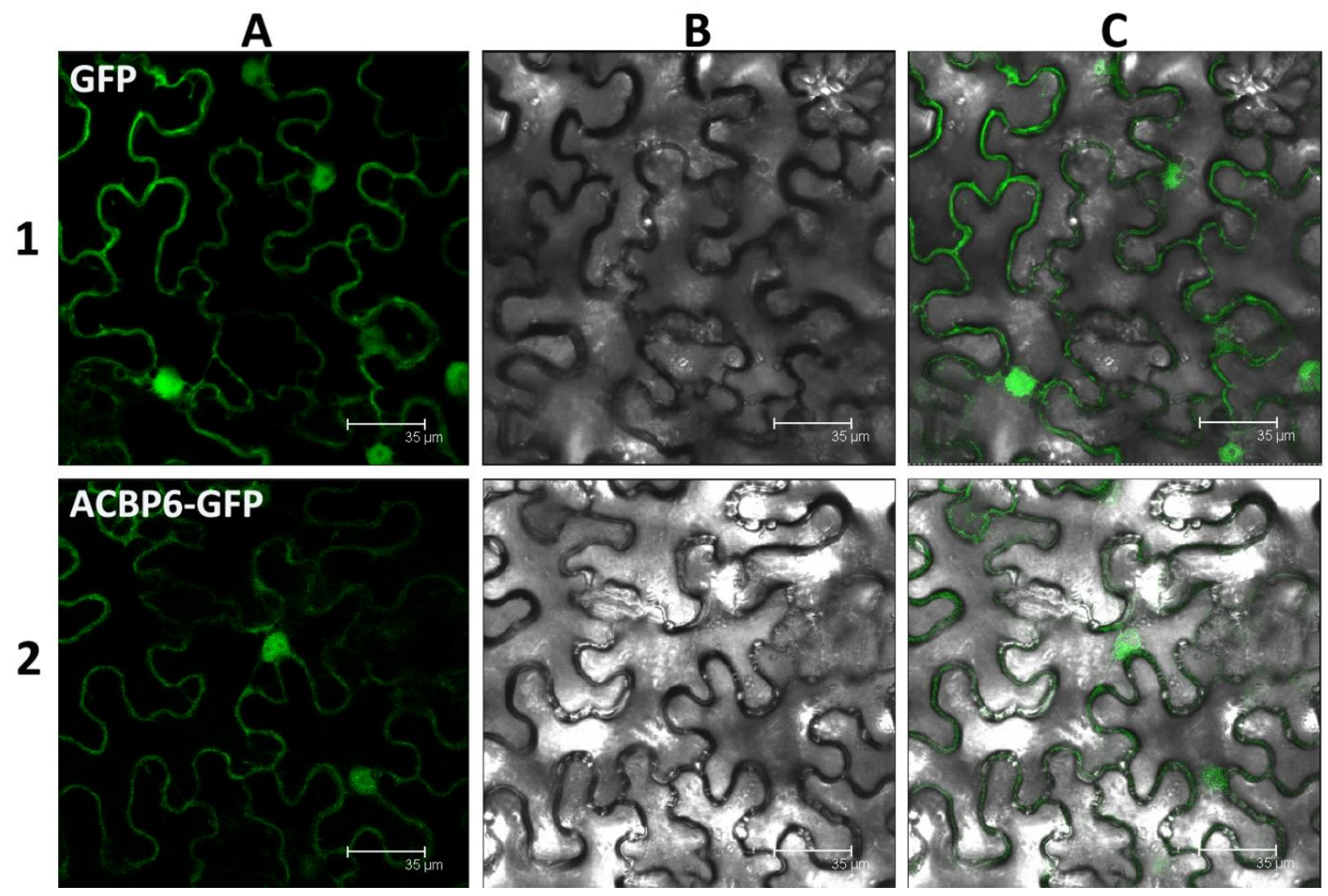